\title{
Egypt: Are Egyptian couples willing to stop at two children? Results of the Slow Fertility Transition Survey [Arabic]
}

Population Council

Follow this and additional works at: https://knowledgecommons.popcouncil.org/departments_sbsr-rh

Part of the Demography, Population, and Ecology Commons, Family, Life Course, and Society Commons, International Public Health Commons, and the Medicine and Health Commons How does access to this work benefit you? Let us know!

\section{Recommended Citation}

"Egypt: Are Egyptian couples willing to stop at two children? Results of the Slow Fertility Transition Survey [Arabic]," FRONTIERS OR Summary. Cairo: Population Council, 2006. 


\section{هل الأزواج المصريون على استعداد للاكتفاء بطقلين؟ نتائج مستح تباطؤ معدلات الخصوبة الخية}

أوضحت نتائج مستح تباطؤ معدلات الخصوبة أن الاتتقال من معدلات الخصوبة الحالية في مصر البالغة 3.2

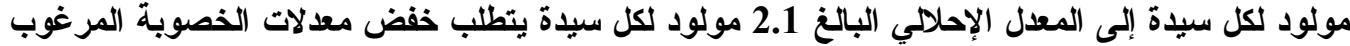

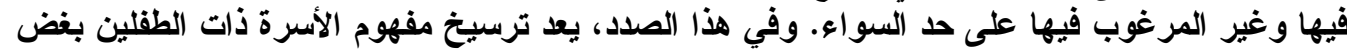

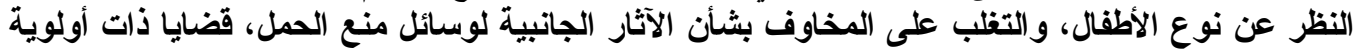
يجب أن يتصدى لها البرنامج القومى للسكان وذلك من أجل الإسراع الجانية بعلية التحول السكانى.

خلقية

بعد أن شهدت معدلات الخصوبة فى مصر خلال فترة الثمانينات ومطلع التسعينات انخفاضا سريعا نسبيا،

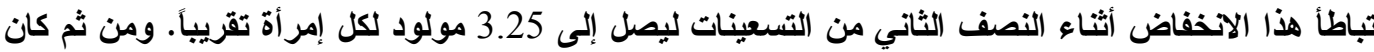

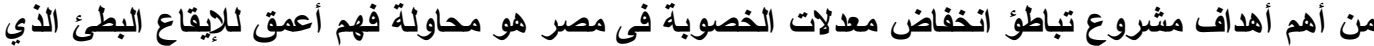

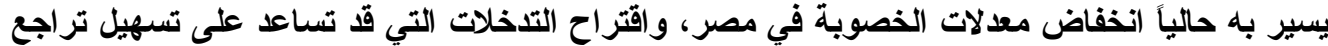
الخصوبة إلى المستوى الإحلالي.

أجرى مشروع تباطؤ معدلات البصدوبة في مصر مقابلات مع عينة فرعية مكونة من 3286 سيدة متزوجة

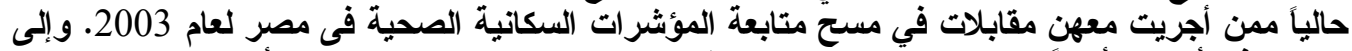

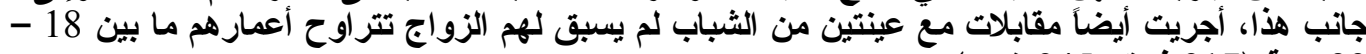
29 سنة (917 فتاة و و945 شاب).

أجريت الاراسة على مرحلتين. الأولى هي جمع البيانات ونفذت بالتنسيق بين مجلس السكان والمركز

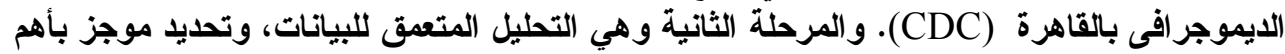

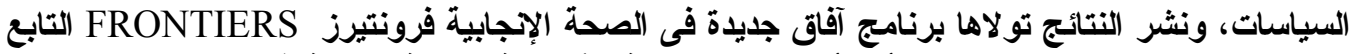

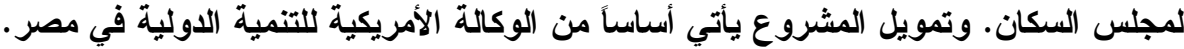

النتائج الأساسية

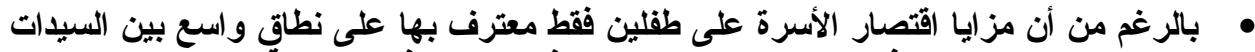

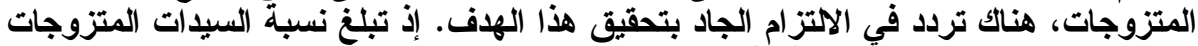

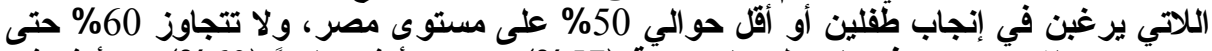

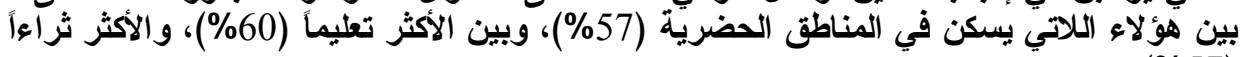
.(\%57)

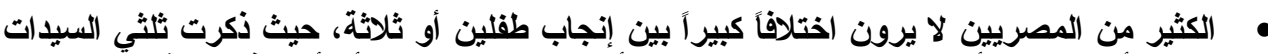

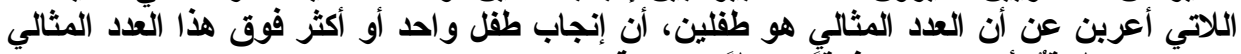

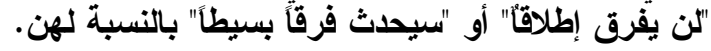

• ذكرت الأغلبية العظمى من النساء اللاتي يردن إنجاب طقلين أنهن يرغبن في إنجاب ولا وبنت،

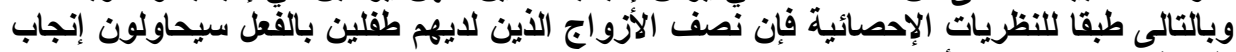
طقل ثالث لإنجاب ولد أو بنت الإحت.

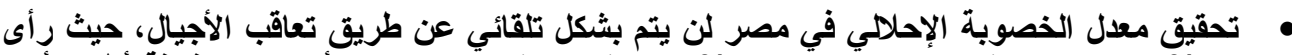

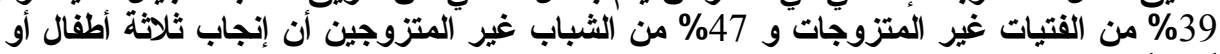

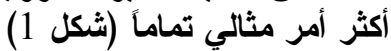




$$
\text { شكل (1) العدد الأمثل للابناء حسب آراء }
$$

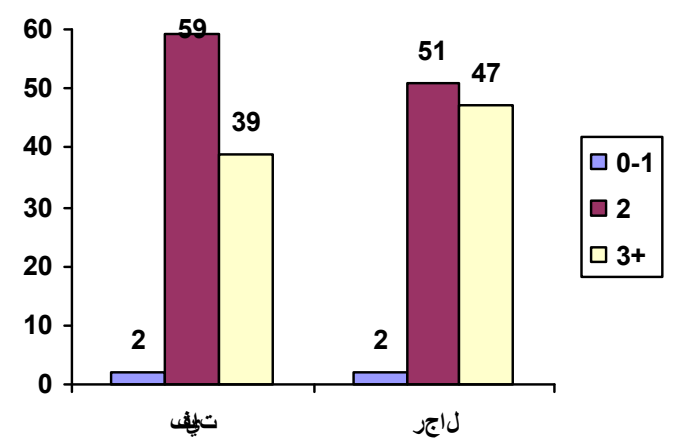

• نسبة كبيرة من حالات الحمل غير المرغوب فيه حدثت بين النساء اللاتي كن يستخدمن وسائل منع

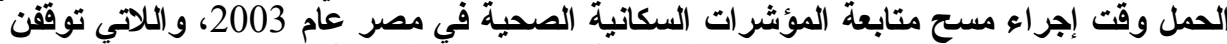

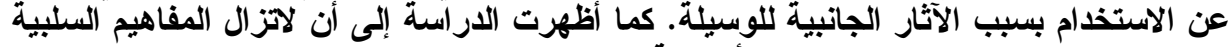

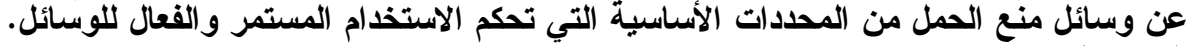

$$
\text { شكل (2) عدد المضاعفات الجانبية التى تعرفها السيدات }
$$

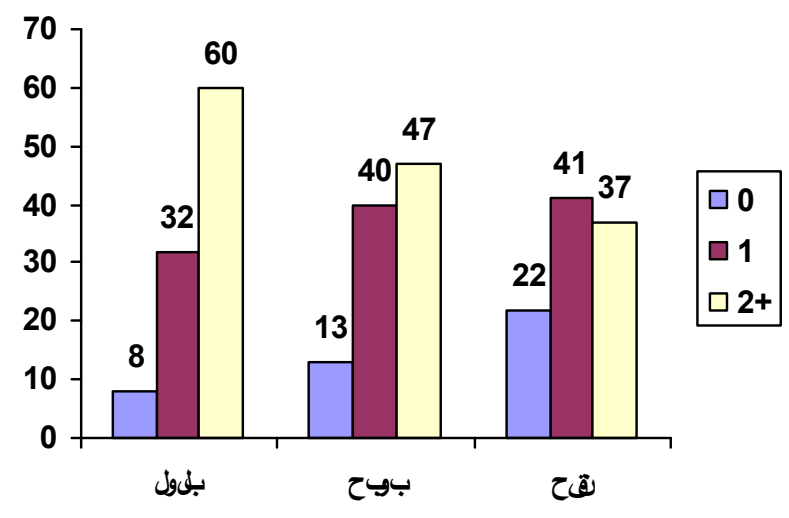

موجز بأهم التوصيات البرنامجية

• الاتثقال من معدل الخصوبة الحالي في مصر البالغ 3.2 مولود لكل سيدة إلى المعدل الإحلالي

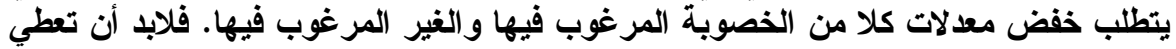

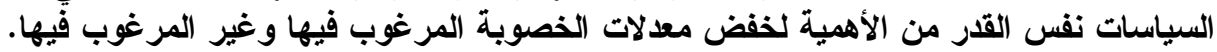

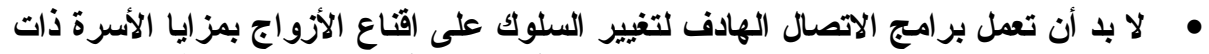

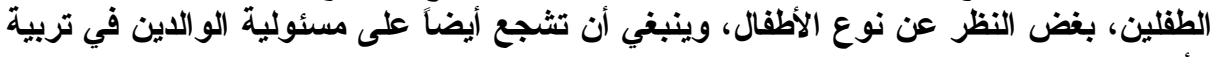

• حقيقة كون أغلب حالات الحمل غير المرغوب فيه تحدث للنساء اللاتي بدأن حديثاً في استخدام

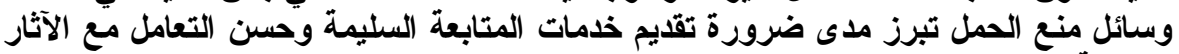


• الثباب والفتيات الذين لم يسبق لهم الزواج هم آباء وأمهات المستقبل، لذلك هم بحاجة لمداخلات

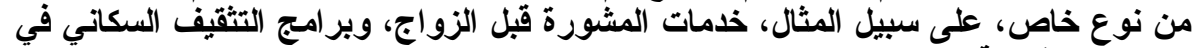
المدارس الثانوية...إلخغ.

استخدام النتائج

• مت طباعة نتائج الدراسة في عدد من المطبوعات (باللفتين العربية والإجليزية) التي تستهدف

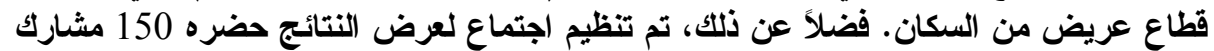

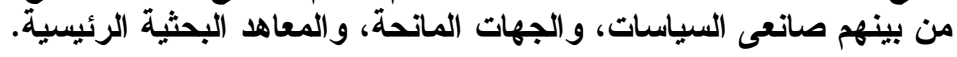

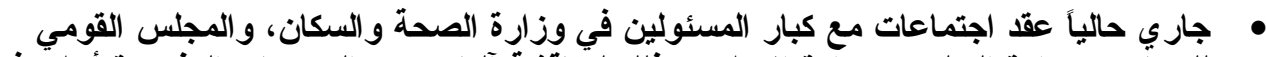

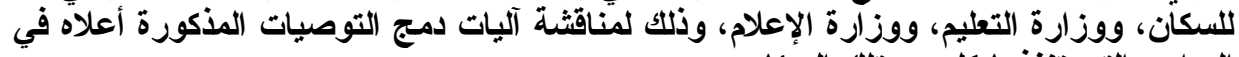
البرامج التي تنفذها كل من تلك النهيئات.

مارس 2006

Casterline, John and Rania Roushdy. Forthcoming 2006, “Achieving Replacement Level Fertility in Egypt: Challenges and Potential Opportunities". FRONTIERS Final Report. Cairo: Population Council.

يقوم مكتب السكان بالوكالة الأمريكية للتنمية الدولية بتمويل برنامج آفاق جديدة فى الصحة الإنجابية

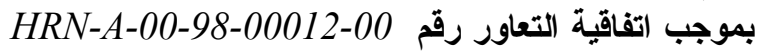


